\title{
REFERENCES
}

1. Finlay.-Intern. Cong. Ophthal., Washington, D.C., U.S.A., p. 144, 1922.

2. Carvill.-Ibid, and also Amer. Jl. Ophthal., Series 3, Vol. VI, p. 885, 1923.

3. Cushing and Walker.-Brain, Vol. XXXVII, p. 349, 1915.

4. Walker. -Arch. of Ophthal., Vol. XLVI, p. 540, 1917.

5. Idem.- "Colour interlacing and perimetry,"-Trans. Amer. Ophthal. Soc., 1916.

6. Traquair.-Edin. Med. Jl., Sept., 1913 ; Ophthal. Rev. p. 72, 1914 ; Brit. Jl. of Ophthal., April-June, 1917.

7. Hess.-Arch. f. Augenheilk., Bd. LXXXIV, S. 1, 1919 ; Ibid, Bd. LXXXV, S. $1,1920$.

8. Köllner.- "Die Untersuchungsmethoden." Graefe Saemisch, Bd: III 3 Aufl., 1925.

9. Idem.-Loc. cit.

\section{OBSERVATIONS ON THE COMPLICATIONS FOLLOWING 4,000 CASES OF CATARACT EXTRACTION}

BY

\section{M. Cruickshank, Major, I.M.S.}

THESE cases represent a part of the work done by Dr. Holland of Quetta, and his staff, during the 1923, 1924, and 1926 seasons at Shikarpur, Sind. The season commences on the first of January and closes at the end of the third week in February. During these three seasons 4,027 cases of cataract were dealt with, 1,322, 1,455, and 1,250 in the respective seasons. While a more or less equal share of the operative work falls to each surgeon, the work of the out-patient department is largely controlled by Dr. Holland, because of his intimate knowledge of the various languages spoken. To me fell the care of the patients in the wards, and I was afforded the unique opportunity of closely examining all the eye cases, noting complications and registering visual results. A system, simple yet effective, was devised whereby everything pertaining to a cataract case could be noted. Each patient on entering the operating theatre had his name written in the cataract book and numbered. Particulars were noted with regard to tension, operative procedure followed, and any complications occurring during the operation. These points, noted in the cataract book were later transcribed to small notebooks used in the wards, the patient's serial number in the cataract book being the number of the page in the small books, containing all the facts relating to the case. It was team work, each member of the team doing his best to make the records as complete and accurate as possible by seeing that the slightest complication, occurring during the operation, however trivial it might appear to himself, was entered against the patient's number and name in the cataract book.

With regard to the selection of patients and the choice of 
operation a word must be said. Patients come long distances by rail and bullock cart, and for many to repeat such a journey is out of the question. In the interests of such patients risks must be taken, which in more favourable circumstances would not be incurred.

The choice of operation.--Though a strong advocate of the intracapsular method, Holland is convinced that it is not necessarily the operation of choice in every case. To the three classes : juvenile, congenital, and secondary cataracts, which Smith considers as unsuitable for the intracapsular operation, Holland ${ }^{(1)}$ adds five :

(1) The "ox eye" type : the very prominent eye found in fullblooded, plethoric individuals, in which vitreous prolapse is liable to occur.

(2) Those cases of double cataract in black-haired, healthy men, aged 35 to 50 years, in whom the zonular fibres are very resistant and require a pressure for their rupture, which leads to vitreous loss.

(3) Those cases of glaucomatous cataract and of cataract in glaucoma, in which a preliminary iridectomy is advised, the lens being extracted with capsulotomy three weeks to twelve months later.

(4) Cases of traumatic cataract.

(5) Those cases where ordinary, legitimate pressure fails to dislocate the lens.

Would there be any advantage in encouraging those lenses to tumble, which resist ordinary pressure and are difficult to dislocate? That was the question asked during the 1923 season, but attempts to tumble hard cataracts meant in the majority of cases loss of vitreous. Some experience with Barraquer's technique during 1924 persuaded me that the answer to the question was, yes, because it was clearly demonstrated that, when the lens was tumbled in phacoerisis, two serious complications, vitreous loss and iris prolapse, tended to be eliminated. If the object of tumbling the lens in phacoerisis is the elimination of these complications, then the initial movement with the erisiphac, which I have described ${ }^{(2)}$ is important. If vitreous loss is to be avoided then the zonular fibres ought to be ruptured from below. The problem awaiting solution was, how to effect this by Smith's method of expression in the capsule. With this problem in his mind Colonel Smith visited India during the winter of 1925-1926 and while there evolved his new technique for the expression of the cataractous lens in its capsule by external pressure alone. ${ }^{(3)}$

In the minds of those who saw Colonel Smith operating by his new method and had the opportunity of putting the method to the test, no doubt remains that the hard lens can be tumbled. without loss of vitreous. 
Of the 4,027 cases which form the basis of this report 3,639 were expressed in the capsule by Smith's methods; 214 by Barraquer's method; 174 with capsulotomy, i.e., 90.3 per cent., 5.3 per cent., and 4.3 per cent. respectively. It is not my intention to compare these methods, because in a clinic where the intracapsular operation is done and only difficult and complicated cases are reserved for capsulotomy, any comparison would be obviously unfair. I desire rather to note how slight alterations in technique tend to increase or decrease certain complications. The percentage results do not necessarily refer to the combined series, and where this is not so the number of cases dealt with is noted and thus any alterations in technique can be judged as having had a fair trial or not so far as numbers are concerned.

\section{Tables giving a Summary of Results}

A. Complications occurring during the operation :

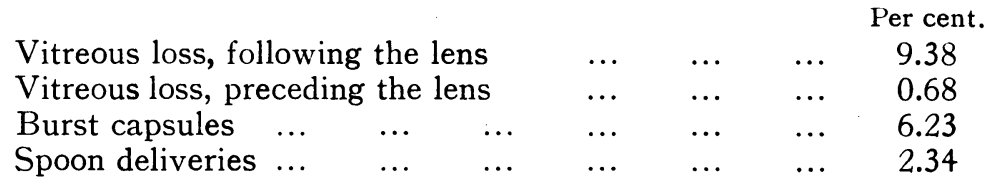

B. Complications occurring after the operation :

Iris prolapse, slight $\ldots . . .0$.

Cases. Per cent.

\begin{tabular}{|c|c|c|c|c|c|}
\hline Iris prolapse, slight & & $\ldots$ & & 226 & 5.63 \\
\hline Iris prolapse, requiring tr & tment & & & 57 & 1.41 \\
\hline Iris incarcerated in the & and & $\cdots$ & & 192 & 4.76 \\
\hline Iritis, serous $\ldots$ & $\ldots$ & $\ldots$ & $\cdots$ & 153 & 3.79 \\
\hline Iritis, plastic $\ldots$ & .. & $\ldots$ & $\cdots$ & 27 & 0.67 \\
\hline Keratitis with pannus for & ation & $\cdots$ & $\cdots$ & 12 & 0.29 \\
\hline Everted corneal flaps & $\ldots$ & $\ldots$ & $\cdots$ & 7 & 0.17 \\
\hline Post-operative glaucoma & $\ldots$ & $\ldots$ & $\ldots$ & 4 & 0.10 \\
\hline Choroidal haemorrhage & $\ldots$ & $\therefore$ & $\ldots$ & 55 & 1.36 \\
\hline Sepsis ... & $\ldots$ & $\ldots$ & $\ldots$ & 64 & 1.58 \\
\hline
\end{tabular}

C. Reasons for non-improvement in vision : i.e., $\mathrm{V} .=$ hand movements or less.

1. Attributable to the operation.

Sepsis

$\begin{array}{rrrrr} & \ldots & \ldots & \ldots & \\ \text { Choroidal haemorrhage } & \ldots & \ldots & \ldots & 55\end{array}$

$\begin{array}{llll}\text { Burst capsule with cortical remains } & \ldots & 27 & 0.67\end{array}$

$\begin{array}{lllllll}\text { Vitreous loss } \ldots & \ldots & \ldots & \ldots & \ldots & 14 & 0.34\end{array}$

$\begin{array}{llllllll}\text { Keratitis } & \ldots & \ldots & \ldots & \ldots & \ldots & 9 & 0.22\end{array}$

$\begin{array}{lllll}\text { Eversion of the corneal flap... } & \ldots & \ldots & 7 & 0.17\end{array}$

$\begin{array}{llllll}\text { Post-operative glaucoma } & \ldots & \ldots & \ldots & 4 & 0.10\end{array}$

$\begin{array}{llllll}\text { Total } & \ldots & \ldots & \ldots & & \\ 207 & 5.11\end{array}$ 
2. Not attributable to the operation.

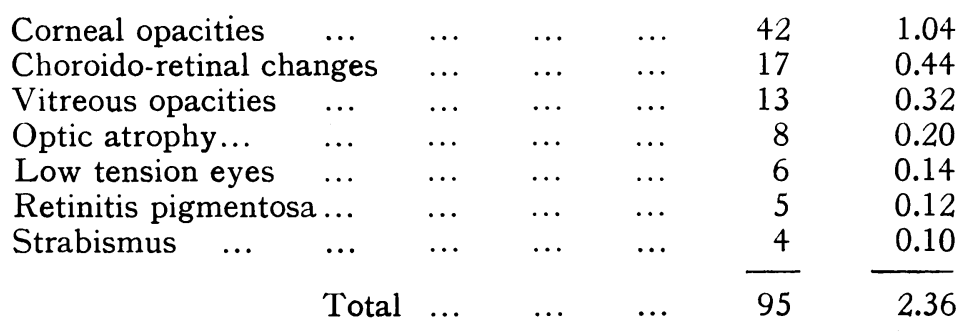

\section{Vitreous Loss}

Though the percentage of vitreous loss is high, 10 per cent., the amount lost was considerable in only a few cases. This is borne out by the fact that in only fourteen cases or 0.34 per cent., was non-improvement in vision associated with vitreous loss. In most it amounted to very little and followed the lens. In those cases, 0.68 per cent., where vitreous was noted as appearing in the wound before the lens presented the delivery was aided with the spoon. In how far small amounts of vitreous loss may affect the visual acuity in after years is one of the many end result problems still unsolved. Major Wright ${ }^{(4)}$ considers as potentially lost, an eye in which vitreous has prolapsed, while Colonel Lister ${ }^{(5)}$, who critically examined 98 of Smith's cases two or three years after operation, concluded that the vision of those cases, in which vitreous had prolapsed, eventually became much better than could have been expected at the time of their leaving hospital. He pointed out that with vitreous loss there is a greater distortion of the cornea temporarily, and that tension and conditions of circulation and nutrition take longer to become re-established than when vitreous is not lost, and further, that in intracapsular operations the loss is less serious than in capsulotomy operations, where the vitreous gets mixed up with lens matter.

Hari Shankar ${ }^{(6)}$ of Muthra describes a method of preventing vitreous escape in the intracapsular extraction of cataract in prominent eyeballs. He states : "if both fornices are exposed to view when looking from the side, the assistant has efficiently managed the lids and the eyebrow, and vitreous should not escape." To avoid vitreous escape he places a small pledget of moist wool on the exposed eyeball, exerting gentle pressure backwards on the globe for about one minute, or, as he puts it, "whilst you mentally count two hundred." This should cause no pain to the patient. He finds that by so doing, "the danger of expulsive haemorrhage is diminished when the tension is plus 
and the vis a tergo of the vitreous is absent or is reduced considerably."

Is vitreous prolapse more liable to occur in the simple or in the combined operation? One would imagine that the slight increase of pressure required to express the lens through a normal or a semi-dilated pupil would lead to increase of vitreous loss, while on the other hand one might consider that the support of a complete iris diaphragm would tend to decrease such loss.

The following figures are interesting, but considering the many factors which tend to bring about vitreous loss, too much importance should not be attached to them.

\begin{tabular}{lllccc} 
& & \multicolumn{4}{c}{$\begin{array}{c}\text { Vitreous } \\
\text { lost in. }\end{array}$} \\
Complete iridectomy & $\ldots$ & $\ldots$ & 650 & 85 & 13.08 \\
Marginal iridectomy & $\ldots$ & $\ldots$ & 144 & 0 & - \\
Peripheral iridectomy & $\ldots$ & $\ldots$ & 216 & 17 & 7.87 \\
No iridectomy $\ldots$ & $\ldots$ & $\ldots$ & 240 & 19 & 7.91
\end{tabular}

The marginal iridectomy was devised by Colonel Smith and the majority of these cases were done by his son, Dr. J. R. Smith. The pupillary margin of the iris is picked up with a fine iris forceps, and holding the iris scissors parallel with the corneal wound a small piece of iris is removed. Stress is laid on the point that the piece of iris margin removed must be such that the sphincter muscle is not cut through completely, otherwise there is danger of the iris splitting radially as the lens passes through the pupil. It is noteworthy that in no single instance where marginal iridectomy was performed did vitreous escape. Comparing the 650 cases in which a complete iridectomy was done, with the 600 cases in which marginal or peripheral iridectomy or no iridectomy was done, the percentage of vitreous loss in the former amounted to 13.08 per cent. as compared with 6 per cent. in the latter.

\section{Iris Prolapse}

Prolapse of the iris is a serious and worrying complication, requiring, as it may, further operative measures for its treatment. The smallest prolapse is a potential source of danger and a source of pain and discomfort to the patient. Minute attention to the replacing of the edges of the coloboma, all important as this is, will not eliminate the trouble. The prolapse may occur after the bandage has been applied, due, in all probability, to the patient squeezing his lids, the escaping aqueous sweeping the iris, or, if an iridectomy has been performed, the edges of the coloboma into the wound.

Maynard ${ }^{(7)}$ advised the use of atropine, both before and after the extraction, but noted that full dilatation of the pupil was not 
maintained after the section of the cornea had been made, and stated that atropine could not take the place of iridectomy.

Maynard held that atropine acted by stimulating the radiating fibres of the iris more than by paralyzing the sphincter, the iris being held taut by the radiating fibres drawing on the pupillary margin from all sides and thus rendering prolapse difficult. Also a wide pupil provides a sluice through which the aqueous escapes readily from the posterior to the anterior chamber, the two chambers being almost thrown into one.

In order to obtain maximal dilatation of the pupil, G. F. Alexander ${ }^{(8)}$ instils one drop of a 5 per cent. solution of atropine one hour before operation. He claims that by so doing iris prolapse is less frequent.

Eserine may be of value in the prevention of iris prolapse on account of its stimulating action on the sphincter pupillae, but $I$ cannot say that I have seen a pin-point pupil result from its use after the extraction of the lens. The semi-dilated, sluggish pupil, however, constitutes a danger and I would prefer a pupil fully under the influence of atropine.

Barraquer uses eserine but in addition makes use of a conjunctival flap and suture.

A conjunctival flap and suture are of definite value. If iris prolapse is to be prevented the suture or sutures must be carefully placed to ensure accurate coaptation of wound edges and thus prevent any sudden loss of aqueous while the anterior chamber is reforming. Again, is an iridectomy essential if iris prolapse is to be prevented? If Barraquer's technique is followed, the eye well under the influence of atropine, and the lens tumbled, then I am satisfied that an iridectomy is not essential. With regard to other methods there is little doubt that a marginal or a peripheral iridectomy gives better results than a complete iridectomy.

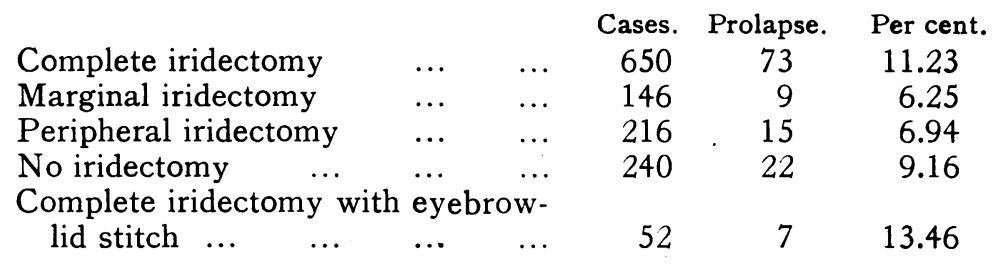

In the peripheral iridectomy cases, the iridectomy was placed centrally, that is in the vertical meridian, in 124 cases, and laterally, that is between the vertical and the horizontal meridians, in 92 cases. In the former, iris prolapsed in eight cases, 6.45 per cent., and in the latter in seven cases, 7.60 per cent., so that the balance is in favour of the centrally placed iridectomy. In the no-iridectomy cases atropine was not used. 
The eyebrow-lid stitch was a mattress suture passed through the thickness of the eyebrow including the peripheral fibres of the orbicularis. This stitch controlled powerful squeezing of the lids on the part of the patient, but did not prevent iris prolapse. Whether or not the prolapse in these cases was due to the discomfort of the stitch causing the patient to interfere with his bandage or rub his eye over or under the bandage, I cannot say.

\section{Burst Capsules}

Even if unassociated with vitreous loss a burst capsule is one of the most serious complications that can attend the intracapsular operation. By bursting the capsule the operation does not resolve itself into a simple extraction with capsulotomy, for the posterior lens capsule has been dislocated, and unless the capsule can be removed entire with the capsulotomy forceps, a very dense aftercataract will result. Even if the capsule has been removed the difficulty of milking out flocculent cortex without further loss of vitreous will be considerable, and may be impossible. It is difficult to see why the majority of burst capsules should occur when a complete iridectomy has been performed. That peripheral iridectomy should account for a certain number of burst capsules is readily understood. Should the button-hole in the iris be too large the narrow band of iris remaining will tend to cut through the capsule; especially is this so if the lens attempts to present through a large button-hole iridectomy.

\begin{tabular}{lllcrc} 
& & \multicolumn{4}{c}{$\begin{array}{c}\text { Burst } \\
\text { Cases. }\end{array}$} \\
complete iridectomy & $\ldots$ & $\ldots$ & 650 & 41 & 6.30 \\
Marginal iridectomy & $\ldots$ & $\ldots$ & 144 & 0 & - \\
Peripheral iridectomy & $\ldots$ & $\ldots$ & 216 & 12 & 5.55 \\
No iridectomy $\ldots$ & $\ldots$ & $\ldots$ & 240 & 9 & 3.75
\end{tabular}

\section{The Drawn-up or Boat-shaped Pupil}

The drawn-up pupil, which is so frequently seen both after expression of the cataractous lens in its capsule, and after extraction with capsulotomy, cannot be dismissed as the result of a hasty or careless replacing of the iris. Kirkpatrick(9) states that "the pupil of an eye from which vitreous escape has occurred during a cataract operation has a characteristic appearance, unless the vitreous escape has been reduced and the iris replaced. This is due to the folding back of the iris which occurs. The lower margin describes a wide curve, and the iris is seen to be shaped like a crescent, the inverted pillars of the coloboma, if an iridectomy has been made, forming the horns." Factors which tend to cause iris prolapse undoubtedly play a large part in the formation of the drawn-up pupil. Incarceration of the iris in the wound, 
vitreous prolapse, a slowly forming anterior chamber, the result it may be of a bad incision or of a carelessly replaced conjunctival flap, any condition which keeps the iris in apposition with the posterior surface of the cornea in the region of the healing wound, especially should healing of the wound be retarded, by the presence between its edges of iris, vitreous, blood or capsule. But why should a pupil continue to become more and more drawn up, weeks after the wound has healed, till little or no pupil is left? It is possible that, as a result of fibroblastic activity, more so in the presence of blood, the iris becomes adherent to the cornea in the region of the section and, as healing goes on, with organization of cellular elements and contraction, the iris or the pillars of the coloboma are stretched, with the result that eccentric pupils of varying shapes are seen.

I have seen many drawn-up pupils with neither vitreous prolapse nor incarceration of iris to explain their presence. That this contraction of adhesions-thread like, pin-point or linear-of the iris to the back of the cornea may be a cause of the malformed, eccentric pupil is possible, apart from actual incarceration of the iris in the wound. Many cases cannot be explained. Perhaps better illumination and greater care might have demonstrated other causes for this annoying and uncertain complication, which though it may not in any way interfere with vision, gives a very bad cosmetic result.

As one can imagine the complete iridectomy gives the true boat-shaped pupil, while the transversely oval pupil and the eccentric circular pupil are seen in those cases where a marginal or peripheral iridectomy or no iridectomy is done. The following table shows the percentage of cases in which adhesions were noted, and, as one would expect, the peripheral iridectomy gives the best results, preventing as it does, ballooning of the iris against the corneal wound as the anterior chamber re-forms.

\begin{tabular}{lllccc} 
& & \multicolumn{4}{c}{$\begin{array}{c}\text { Cases. } \\
\text { Adhesions } \\
\text { noted in. }\end{array}$} \\
Complete iridectomy & $\ldots$ & $\ldots$ & 650 & 33 & 5.07 \\
Marginal iridectomy & $\ldots$ & $\ldots$ & 144 & 6 & 4.30 \\
Peripheral iridectomy & $\ldots$ & $\ldots$ & 216 & 6 & 2.70 \\
No iridectomy $\ldots$ & $\ldots$ & $\ldots$ & 240 & 10 & 4.10
\end{tabular}

\section{Choroidal Haemorrhage}

In Sind the incidence of glaucoma is high and the chances of meeting choroidal haemorrhage as a complication are very great. These patients clamour for operation, knowing that in operation lies their only hope of some vision, however little it may prove to be. They practise all sorts of deceptions in order to pass the examining surgeon, and even when finally refused operation, they 
are found later sitting quietly amongst those who are being prepared for operation. One striking fact which the work at Shikarpur has demonstrated is the effect that the routine use of the tonometer has in decreasing the number of cases of choroidal haemorrhage. Tonometry, however, useful as it is, can only serve as a guide in helping one to decide what operative measures can be undertaken with safety in dealing with eyes in which tension is raised. Other factors must be considered; how long the tension has lasted, the presence of arterio-sclerosis, the blood pressure, the presence of intercurrent disease; and the perplexing feature is that in spite of all precautions, choroidal haemorrhage will be met with. If the choroidal vessels are healthy, then the degree of intraocular tension will be a matter of less moment, but a slight increase of tension, in a patient the subject of general arterio-sclerosis, will call for care and judgment. Those who have seen many cases of choroidal haemorrhage, both expulsive and concealed, will agree with W. R. Parker ${ }^{(10)}$ when he states that, while the three cases of expulsive haemorrhage reported in his series of 1,421 cases, occurred in patients with advanced arteriosclerosis, yet "there was no indication that a haemorrhage was more likely to occur than in any one of a large number of patients with equally severe symptoms on whom a similar operation was successfully performed." If hypertension is present and the occurrence of haemorrhage seems possible then a capsulotomy might be performed, or Hari Shankar's method of applying gentle pressure to the globe for a minute or longer might be resorted to. In one instance, in which the tension was $50 \mathrm{~mm} . \mathrm{Hg}$ and the patient complained of pain on completion of the corneal incision, I left the lens in position, bandaged the eye, gave the patient a quarter of a grain of morphia and sent him back to bed. Seven days later I removed the lens in the capsule by Barraquer's method, with no untoward results. No iridectomy was done, a central black pupil remained and the visual result was very good. One might infer here that pain pointed to dilating intraocular vessels, which were prevented from rupturing by leaving the lens in position and bandaging the eye and thus maintaining what intraocular pressure remained. In some doubtful cases I have made the incision, put a moist pad on the eye and waited fifteen minutes before going on with the operation, and have not so far seen a haemorrhage in cases so treated.

E. E. Maddox ${ }^{(11)}$ reports a case in which he successfully extracted a cataract in the capsule, the patient having lost the other eye as a result of choroidal haemorrhage. A preliminary iridectomy was done one week before the extraction. Calcium lactate was given the night before, and morphia and bromide on the morning of the operation. Before commencing the operation venesection was 
done and the episcleral veins pricked. A corneal suture was employed and a pressure bandage applied. After operation hot turpentine stupes were applied to the abdomen, and the feet kept warm to promote circulation of the blood in the abdomen and the lower extremities.

Osmotic therapy, as suggested by Duke-Elder, ${ }^{(12)}$ would appear to be of definite value as a preliminary to operation, in cases of hypertension. The difficulty, however, remains with those cases in which increase of tension is not a feature.

I make no mention of post-operative glaucoma as a complication, because so few cases of this are seen, due doubtless in part to the fact that difficulty is experienced in following up cases after operation, in India.

I am indebted to Dr. Holland for the help he has given me and for the opportunity afforded me of reviewing the work done, under his direction, at Shikarpur.

\section{REFERENCES}

1. Holland, H. T.-Indian Med. Gaz., Vol. LVII, p. 296, 1922.

2. Cruickshank, M. M.-Brit. Jl. of Ophthal., Vol. IX, 1925.

3. Smith, H. - Arch. of Ophthal., Vol. LV., 1926.

4. Wright, R. E.-Reports of the Madras Eye Hospital, 1923,

5. Lister, A. E. J., cited Smith. H.-Treatment of Cataract, 1910.

6. Hari Shankar.-Indian Med. Gaz., Vol. LVIII, p. 251, 1923.

7. Maynard, F. P.-Manual of Ophthalmic Operations, p. 114, 1920.

8. Alexander, G. F.-Trans. Ophthal. Soc. U.K., Vol. LXXVIII, p. 16, 1924.

9. Kirkpatrick, H.-Cataract and its Treatment, 1921.

10. Parker, W. R.-Trans. Section on Ophthal., Amer. Med. Assoc., 1921.

11. Maddox, E. E.-Amer Jl. of Ophthal., p. 726, 1920.

12. Duke-Elder, W. S.-Brit. Jl. of Ophthal., Vol. X, p. 30, 1926.

\section{ANNOTATIONS}

\section{The Effect of Eyestrain on the Output of Linkers in the Hosiery Industry}

In the April number of this year we commented on a report of the Medical Research Council on the effect of illumination in fine work (type-setting by hand). Another report of the Industrial Fatigue Board approaches the subject from another side, i.e., the possible advantages of reducing the necessary accommodative work with the aid of glasses. The experimental work was done by Messrs. H. C. Weston and S. Adams, while Mr. Laws was responsible for the estimation and correction of refraction in the 